\title{
Life Cycle Assessment and Judgement
}

\author{
Christopher Nathan (1D) Stuart Coles
}

Received: 22 October 2019 / Accepted: 14 September 2020 / Published online: 26 November 2020

(C) The Author(s) 2020

\begin{abstract}
It has become a standard for researchers carrying out biotechnology projects to do a life cycle assessment (LCA). This is a process for assessing the environmental impact of a technology, product or policy. Doing so is no simple matter, and in the last decades, a rich set of methodologies has developed around LCA. However, the proper methods and meanings of the process remain contested. Preceding the development of the international standard that now governs LCA, there was a lively debate in the academic community about the inclusion of 'values' within the process. We revisit this debate and reconsider the way forward for LCA. We set out ways in which those outside of science can provide input into LCAs by informing the value assumptions at stake. At the same time, we will emphasize that the role of those within the scientific community need not (and sometimes, will inevitably not) involve value-free inquiry. We carry out this exploration through a case study of a particular technology project that sought ways to produce industrial and consumer products from algal oils.
\end{abstract}

Keywords Life cycle assessment $\cdot$ Responsible innovation $\cdot$ Technology assessment $\cdot$ Sustainability

C. Nathan $(\bowtie)$

Department of Politics, University of Warwick, Coventry CV4

7AL, UK

e-mail: c.m.j.nathan@warwick.ac.uk

S. Coles

Warwick Manufacturing Group, University of Warwick, Coventry CV4 7AL, UK

\section{Introduction}

It has become standard for researchers carrying out biotechnology projects to do a life cycle assessment (LCA). This is a process for assessing the environmental impact of a technology, product or policy. Doing so is no simple matter, and in the last decades, a rich set of methodologies has developed around LCA. Reflecting this complexity, the technique has its own dedicated journal (the Journal of Life Cycle Assessment); there are several commercially run, well-marketed databases of the impacts of different substances; and in 2009 Time magazine named life cycle assessment one of the ' 10 Ideas Changing the World Right Now'. However, the proper methods and meanings of the process remain contested. One practitioner argues that LCA as an international standard is failing because competing interpretations of it are so widespread [1]. Preceding the development of the international standard that now governs LCA, there was a lively debate in the academic community about the inclusion of 'values' within the process. We revisit this debate and reconsider the way forward for LCA. It is a goal of this paper to set out ways in which those outside of science can provide input into LCAs by informing the value assumptions at stake. We conclude by suggesting that the role of those within the scientific community need not (and sometimes, will inevitably not) involve value-free inquiry and proposing that researchers embrace this state of affairs. 
We carry out this exploration through a case study of a particular technology project and use it in order to illustrate broader points about the way that technology is assessed. The project is an EU FP7 project called BISIGODOS. It ran from 2013 to 2017. It investigated ways in which to use algal oils to make consumer and industrial products such as inks, cosmetics and foodstuffs. Such products are currently manufactured with a petrochemical feedstock. There are numerous other ongoing efforts to identify how to make useful products with algal oils (such as the MIRACLES project), and indeed the use of biofuels is the most commercially developed such effort. In the BISIGODOS project, the algae were grown using carbon dioxide that resulted directly from the industrial emissions of a cement factory. Algae might similarly be produced using carbon dioxide emissions from other industrial processes such as steel factories or thermal power plants. One might expect such an arrangement to count favourably for the products from the point of view of sustainability, both because this source of carbon dioxide is cheap and readily available and because the manufacture of the final set of products will have an element of carbon offsetting built into it.

\section{The Aspiration of Neutrality}

Life cycle assessment is sometimes described amongst the 'tools' that those seeking to carry out responsible research and innovation (RRI) might apply [2]. While RRI has been keen to include LCA within its remit, LCA practitioners themselvesguided in part by the international standards that govern the process - are sometimes coy about the idea that LCA involves making judgements of value. This contrasts with the emphasis of RRI upon encouraging and facilitating reflection upon the ethical and social aspects of a technology from its inception. Our focus in this paper is on this coyness in the LCA world concerning the way that value judgements find their way into life cycle assessments.

There is a certain attraction to the ideal of having a tool that objectively assesses the impact of products, technologies or policies. Economic decisions run through the process of technology development and deployment. We need to decide where research efforts will be directed and, especially, which research projects will be funded. We need to decide what policies will apply to those in a position to produce a product: what regulatory and fiscal regime will apply? Individually, we also make consumption decisions, and these may be influenced by the standing of the product with regard to sustainability goals. Companies, too, will wish to understand the overall impact of the products and processes that they create in order to align them with their own sustainability goals. Such economic decisions are not themselves technical and carry with them a dose of politics. Would not it be valuable both for the purposes of making better decisions, and for making decision processes transparent, to have a tool that can assess a product or a process without making implicit or explicit controversial claims about - for example - what overall direction a research area ought to take, or how risk for future generations should be applied, or what the expectations should be upon individuals to effect or accept changes in their economic status? It would thus be highly useful to have an objective measure that guides decision-making.

Put more concisely, the thought is this: discussions about resource allocation are often fraught, political or ideological; assessments of the relevant facts are highly complicated and thereby liable to have their conclusions influenced by the independently held views of those carrying them out; it is therefore useful in the extreme to have a process that can identify the relevant inputs, compare them and provide an assessment of the outputs. LCA is or should be such a process.

\section{Where Values Relate to the LCA Process}

The above-described objectivity is an aspiration for LCA that is sometimes put forward baldly and, even where it is not, describes something of the attraction of the tool. Nonetheless, such an aspiration is not universal, and a sizeable part of those developing and using the standard see it as a method for making transparent the reasoning process about how best to judge the impact of a technology or policy, rather than as a way of outsourcing or avoiding judgement. Consequently, the sophistication of LCA methods is partly a reflection of the explicit or implicit recognition that doing an LCA involves making judgements of value. That is, making judgements of what is more or less important, of what should be done, of how benefits or harms or risks should 
be distributed, or of how all those matters should be governed. ${ }^{1}$

There are two areas of decision for those designing an LCA that will touch upon issues of value. The first area is concerned with the impacts of a technology. How are these compared, and how are they selected? The second area is concerned with the description of the technology itself. How should we understand the extent and proper delineation of the system that is under assessment?

\section{Impact Category Selection}

Each of those areas can again be subdivided. ${ }^{2}$ Impacts can be divided into different impact categories. The ISO standard on LCA sets out eighteen categories of impact. The ReCiPe 2016 method sets out eighteen midpoint and three endpoint impact categories. In this method, endpoints are broad areas such as damage to ecosystems and damage to human health, whereas midpoints are pathways to those damages such as global warming/ climate change, ionizing radiation and particulate matter. Consider the issue of which of those eighteen impacts to compare. The BISIGODOS assessment examined five impact categories:

- Climate change

- Ozone depletion

- Terrestrial acidification

- Freshwater eutrophication

- Photochemical oxidant formation

Why would an LCA ignore any of these eighteen? The answer is that a category may be inapplicable to the technology, or that an assessment of a category may be excessively complex, given the goals of the overall assessment. Consider the category of light pollution. It is obscure how it might be useful to assess algal oil-

\footnotetext{
${ }^{1}$ Note that assessments can be aimed at different kinds of object. The goal may be to assess the impact of a product, such as biofuels. Or it may be to assess the impact of a policy, such as a subsidy for biofuels. The standards guiding LCA demand that the goal of the assessment is explored at the outset and is continuously returned to throughout the assessment. After goals are specified, the inputs of the process under assessment are inventoried, an analysis of the impact is made of each of these inputs, and these impacts are combined in order to provide an overall assessment. From herein we will, for the sake of brevity, talk of LCA as an assessment of a technology.

${ }^{2}$ Here we draw and build upon the classification of value judgements in LCA put forward in Wender et al. [3].
}

based shampoos for their impact upon light pollution. The impacts are prima facie both minuscule and hard to predict, and the margin of error would make any data questionable.

The selection criteria for which impacts are to be selected might be put in starker terms:

The selection of impact categories depends on the purpose of the LCA, e.g. what kind of decision is going to be taken based on the LCA... Basically, selection of impact categories is a matter between the commissioner and the practitioner...([4], p. 31)

Insinuated, if not logically implied, in such wording is the notion that the purpose of the LCA follows from what the LCA commissioner chooses to aim at, with some input from the practitioner about what is feasible, and that the proper selection criteria follow largely from the commissioner's purpose. Such a view gives a wider latitude than is now fashionable to the discretion of those commissioning LCA. Is it possible for an LCA, given its context, to be assigned the wrong goals? Can an assessment's goal selection be criticized by others? In the design process as described by the ISO, the question of the goal of the LCA is repeatedly returned to. Those answering at each stage the question of what the goals are must be appealing to some criteria for their decision that go beyond their personal preferences or professional interests. If the question is to be answered with external criteria, then it must be possible to give the wrong answer.

This can be taken a step further by looking at the method by which the impact category is calculated. These impact assessment methodologies vary not only in the manner of the calculation but also in the output of the category itself. Common methodologies include CML 2001 [5], EF/ILCD [6] and Impact 2002+ [7]. A new method, ReCiPe [8], proposed in 2008 and updated in 2016, was initially an amalgamation of CML and another common approach, Eco-Indicator 99 [9]. The choice of methodology was noted as being important by Dreyer et al. [10], where the results for an LCA were largely similar in energy-related impact categories but considerably different in toxicity-related categories. Choice of impact assessment methodology must therefore also be agreed by the commissioner and practitioner as part of the scope, as the methodology must be accurate for the impact categories that have been chosen to 
be desirable. It therefore stands to reason that it is possible to not only give the wrong answer on one's own terms but also to give the wrong answer calculated by the wrong methodology.

It is clear from the ISO 14040 (2006) that impact category selection depends upon being able link the environmental effect to the cause, with some degree of certainty. The standard puts the process in the following terms:

\section{§ 4.4.2.2.2 - Environmental relevance encom-} passes a qualitative assessment of the degree of linkage between category indicator result and category endpoints; for example high, moderate or low linkage. ${ }^{3}$

The criteria for selecting indicators are concerned with the ability to connect the indicator to an impact. Where the effect of a category is reversible, brief, localized and small, it is unlikely to be included in the impact assessment.

Interestingly, the BISIGODOS project does not include an assessment upon the category of primary resource depletion. Depending on the baseline, its effects on this category would certainly be positive in comparison with the alternative industrial products that are available on the market today. The environmental burden of the carbon dioxide feedstock lies with the primary production process of the cement as it is a secondary (waste) product. The algae feed and the accompanying conversion technology would have some depleting

\footnotetext{
${ }^{3}$ The standard continues:

§ 4.4.2.2.4 - The environmental relevance of the category indicator or characterization model should be clearly stated in the following terms:
}

a) The ability of the category indicator to reflect the consequences of the LCI results on the category endpoint(s), at least qualitatively

b) The addition of environmental data or information to the characterization model with respect to the category endpoint(s), including

- The condition of the category endpoint(s)

- The relative magnitude of the assessed change in the category endpoints

- The spatial aspects, such as area and scale

- The temporal aspects, such as duration, residence time, persistence and timing

- The reversibility of the environmental mechanism

- The uncertainty of the linkages between the category indicators and the category endpoints effect in many cases. Still, if products that are currently made using petrochemical feedstocks are made instead using a renewable source, then one would expect that the primary resource of oil is depleted far less than it otherwise would be. This is a point at which an LCA touches upon a deeper issue of contention about global politics and the direction of technology. The inclusion of stores of oil as a primary resource is itself not uncontroversial as a category for measuring the impact of a technology, given that a sizeable group argues that such resources are better left untouched both for sustainability and global political reasons [11]. In this sense, the BISIGODOS assessment claimed less for itself than it might have done and in doing so applied a more ambitious environmental standard.

Aside from that particular policy issue, the appeal to uncertainty raises another normative issue. This is the extent to which claims that fall under the rubric of 'scientific' ought to be carried with certainty. For example:

Scientists have less confidence...in the relationship between climate forcing and physical damage than they have in the relationship between climate forcing and greenhouse gas emissions. The choice between those two indicators [i.e., environmental damage indicators and greenhouse gas emissions] is therefore a tradeoff between scientific reliability and the ability of the indicator to reflect our concerns [12].

We might draw a connection to the precautionary principle in science and technology policy, which demands limits on actions that have more uncertain consequences. ${ }^{4}$ Insofar as the precautionary principles applies, it may demand the inclusion of outcomes about which there is less confidence of knowledge into an LCA, since that principle demands greater responsiveness to uncertainty.

\section{Weighting}

An area that is more difficult to resolve, and that brings us more immediately to the heart of the issue of the purpose of LCAs, is that of whether, and if so how, to compare the different impacts once they have been assessed. In the

\footnotetext{
${ }^{4}$ For doubts about the precautionary principle, see Read and O’Riordan [13], but c.f. John [14].
} 
history of its development, the idea of 'weighting' different kinds of environmental impact has been controversial. ${ }^{5}$ Can it be meaningful to take the disparate impacts of a product upon, for example, eutrophication (measured by excess macronutrients in water leading to algae growth), ozone depletion and 'climate change' (measured by carbon dioxide production), and to assign one single number to them? If the product is re-engineered so that it leads to more carbon dioxide production but less eutrophication, what effect should that have upon the product's singular weighted 'impact'? It would seem that the answer is indeterminate, or is supervenient upon other assessments of, for example, the extent to which biodiversity is an independent value, or the extent to which we should be concerned about toxicity to immediate populations, in comparison with long-term climate change effects to future generations.

In discussions of the demerits of weighting, one is particularly likely to come across assertions of the importance of the objectivity of LCAs. The international standard itself contains such an assertion, in stating that procedures involving weighting of different environmental effects are 'based on value choices and not scientifically based' and thereby are not be used in LCAs aimed at public consumption. ${ }^{6}$ The assessment in BISIGODOS, accordingly, does not make any attempt at weighting the different impact categories that it sets out; it sets out the five selected categories and analyses each separately.

We will return to such arguments below. For the moment, note that weighting of outputs may include judgements about:

- Time discounting. Should harms or benefits to members of future generations count for less than harms or benefits to members of current generations? We tend to discount costs and benefits for ourselves that are far off in the future and might similarly do so for future generations. If so, then our weighting might place somewhat less weight on impacts that will occur in the future, such as climate change, in comparison with immediate impacts, such as eutrophication or light pollution. Others,

\footnotetext{
${ }_{5}^{5}$ Similar issues are faced by the 'normalization' of outputs, which faces the issue of how to choose normalization references. See Laurent et al. [15].

${ }^{6}$ ISO 14044 (2006), sn. 4.4.3.4 and 4.4.5
}

however, argue that time discounting carries unacceptable implications. ${ }^{7}$

- Effects on different communities. Where an impact is likely to land more heavily upon those who are less well off, it might be argued that the marginal disutility of that impact will be greater and so should be weighted higher. Alternatively, it may be held that it is not the role of technologists to correct for social injustice in a direct way and that accordingly their assessments should assume equality of impact across communities for any given output.

- The relative disvalue of risk to life and economic costs. A full assessment would need to make comparisons of risks to life and economic costs. Policymakers are used to making such comparisons, but the background methodology is by no means uncontroversial [17].

\section{System Boundary Definition and Functional Unit Selection}

There are two more subtle ways in which judgements of value enter the LCA process, running not through the way in which the outputs of an assessment are understood but instead based in how the object of assessment is defined at the outset. LCAs carry judgements not just about weighting but also judgements relating to individual behaviour and government policy. For any given product, what assumptions are to be made about how much people will seek to consume, how they will dispose of it, the commercial effects on other industries of introducing the product, the potential beneficial environmental effects on the production of other products and how far these will be exploited. What should we expect of behaviour change? How many T-shirts a year do you assume people buy and dispose of? How do people dispose of their clothes? What are the commercial effects on other industries of producing T-shirts in one way rather than another? What are the potential beneficial environmental effects on the production of other products of producing T-shirts in one way rather than another? In order to give an account of the impact of a product on the environment, one requires an account of the relevant alternatives at stake: of how to

\footnotetext{
${ }^{7}$ There is a good discussion of time discounting as it relates to climate change indicators in Hertwich et al. [12]. For arguments against pure social discount rates, see Caney ([16], pp. 320-342).
} 
describe the world with, and without, the product. The relevant worlds to compare can be variously described; there is not obviously a natural fact-of-the-matter about which is the closest possible worlds.

A key question is whether one includes changes in human - and especially, economic — behaviour that the product may have. Attributional LCA will not include such considerations, whereas consequential LCA will. Such matters can make a difference:

The change in the balance between supply and demand for a good or service can have farreaching impacts. For example, through an attributional analysis, Searchinger et al. [18] calculated US corn-based ethanol resulted in a $20 \%$ decrease in greenhouse gas emissions compared to conventional gasoline. However, in a consequential analysis to account for policy-driven increases in output of bio-based ethanol, they calculated a $47 \%$ increase in emissions compared to gasoline, due to assumptions in land use changes induced by predicted higher prices of corn, soybeans and other grains from anticipated additional demand for corn starch for ethanol production [19]. ${ }^{8}$

Some argue that since 'Most LCA studies are actually aimed at decision support involving a choice or substitution between two product systems', it is usually misleading to use an attributional analysis [22]. ${ }^{9}$ Others, however, emphasize that not only are most LCAs in fact attributional but also that attributional LCAs are useful in the context of understanding the workings of the particular aspects of a product:

In a nutshell, attributional life cycle assessment focuses on describing the environmentally relevant impacts of the activities that contribute to a specific property of a product or process, while consequential assessment describes how environmentally relevant impacts will, or could, change in response to the studied action or decision... Neither general

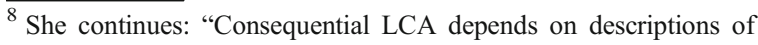
economic relationships embedded in models. It generally attempts to reflect complex economic relationships by extrapolating historical trends in prices, consumption and outputs. This adds to the risk that inadequate assumptions or other errors significantly affect the final LCA results." On the relation between consequential and attributional LCA, see also Suh and Yang [20] and Plevin et al. [21].

${ }^{9}$ For development of such reasoning see Weidema [23].
}

rule sets nor detailed descriptions of specific cases can prevent deliberate misuse of LCA. LCA is like a sharp knife. It can be used and abused. A doctor can certainly do well with a sharp knife, a murderer presumably not. It makes no sense to blame knifes or LCAs for misuse [24].

(M [6], 132)The decision of whether to embrace the greater certainty that goes with an attributional LCA, or the enhanced ability to answer policy questions that goes with a consequential LCA, is one value question facing those commissioning assessments. Making such a decision for a publicly declared LCA will depend in part on one's account of the best way to communicate findings, which itself may depend on one's account of the most pertinent aspects of a possible assessment - and pertinence, of course, is not an easy metric to measure. Furthermore, insofar as changes in behaviour are to be included in the assessment, one will face questions about how to value different outcomes. Purely economic or utilitarian approaches will be theoretically simple; appeals to other systems, such as a Rawlsian structure or Sen's capabilities view, may better stand up to scrutiny [25].

The BISIGODOS LCA included an attributional analysis using a commercial dataset and supplemented this with an economic analysis. The issue of how to determine the functional unit is well-illustrated in the BISIGODOS assessment. That assessment involved an analysis of each product separately. One might instead assess the impact of, for instance, algal oil-based surfactants, given that other products, such as supplemental foodstuffs or shampoos, are already produced using algal rather than petrochemical feedstocks. The question is whether the relevant comparator possible world is one in which other products except for the one being assessed are produced using petrochemical, or algal, means. The answer depends on the policy question at hand: it may be 'should we switch production of this one product towards non-petrochemical feedstocks?', or it may be 'should we engage in a wholesale effort at switching as many products as possible towards nonpetrochemical feedstocks?'. The LCA might prima facie be expected to come out somewhat more in favour of the algal oil products in the latter kind of assessment, given production economies of scale. The economic analysis that was carried out separately inevitably contained some uncertainty. Nonetheless, given that the technology under development would, if successful, be deployed for numerous products in diverse sectors, it is arguable 
that a whole system analysis that incorporated both economic and environmental considerations would have given a more useful (and indeed, positive) result.

\section{Section Summary}

We can briefly summarize the points put forward in this section as follows. In order to make a meaningful assessment, one will need to make value judgements concerning (i) what precisely one is to assess; (ii) how to make comparisons; and (iii) how to respond to uncertainty. ${ }^{10}$

\section{On the View that Judgements Can Be Made but Should Not Be Made Public}

Given that such judgements must be made in LCA, what is the best response? Where should they be located, who should make them, and how? It would not be sufficient to assume the attitude of objectivity, since the judgements will be made, whether implicitly or explicitly. Some take the view that a central pillar of an appropriate response is that certain of the most controversial judgements should be absent from assessments that are made public. Such an idea appears in particular with regard to the issue of weighting. Thus, ISO 14042 states, 'Weighting shall not be used for comparative assertions disclosed to the public'. Schmidt and Sullivan provide some reasoning for such an approach. Their central claim is that 'regional variations in legislation, consumer values, monetary valuation, existing weighting sets and expert opinions' imply that 'no globally agreed upon weighting set is likely to be derived'. From this they conclude, 'For any external communication, none of the quantitative weighting sets can be used' [27] ${ }^{11}$

The reasoning here needs some cashing out. Pizzol et al. criticize the position of the ISO on the grounds that it 'seems to generally disregard the scientific basis of anything that is not based on natural sciences' and furthermore hold that it 'glosses over the fact that LCA, and environmental modelling in particular, is full of value choices' [29]. However, charitably, we might emphasize that it is a concern about which results are suitable for public communication that is the concern here, and not about the fact of value judgements in general.

\footnotetext{
${ }^{10}$ For a similar way of dividing up the field, see Steen [26].

11 This follows the characterization put forward in Hofstetter [28].
}

Still, why does the concern apply only to elements of LCA that are intended for public communication? The majority of LCAs is not made public. Why is weighting by implication acceptable for assessments made for the purposes of judgements by individual scientists or within research groups or consortia or amongst policymakers? Here is one attempt to construct the argument:

1. Insofar as they involve values, international standards should be based on agreed-upon values.

2. Weighting standards are not agreed upon, and agreement is unlikely to be attained.

So,

3. The international standards for LCAs should not involve weighting.

Call this the International Standards argument. Indeed, ISO standards are worked on by committees of experts, with the goal of forming agreements. Nonetheless, this argument's second premise claims too much: as we will see in subsequent sections, there are ways that assessors can bring in the views of stakeholders, or provide multiple outputs, that involve appeals to value but do not do so in a way that demands their priority in the context of disagreement. The first premise, furthermore, also claims too much. Whereas the ISO 14042 proposes only avoiding weighting in LCAs aimed at the public, this argument concludes that even those LCAs that are to be used internally within an organization should not use weighting. That view is extreme.

Here is a different argument:

1. Public understanding of technology assessments is likely to focus upon their headline conclusions.

2. Weighted LCAs will involve headlines that are likely to be misinterpreted and given an improper place in public deliberations if their underlying weighting is not part of their public understanding.

3. General public understanding of weighting is unlikely.

So,

4. Public understanding of weighted LCAs is likely to be misinterpreted and given an improper place in public deliberations. 
But,

5. Researchers should not make public releases of technology assessments that are expected to be misinterpreted and given an improper place in public deliberations.

Therefore,

6. Researchers should not make public releases of weighted LCAs.

Call this the public understanding argument. This argument does reach the conclusion aimed at by Schmidt and Sullivan and by the quoted line above from ISO 14042, namely, that weighted LCAs are not suitable for public consumption. It focuses on the challenges raised by burying normative assumptions in weighting calculations. However, many will doubt that premise (3) can be brought to work in the way that the argument seeks. It may be the case that with the requisite degree of care about presentation, the controversies that underly an assessment can be made sufficiently clear to the public. ${ }^{12}$ Furthermore, the argument does not capture the reasoning at hand. It focuses only on the way that public assessments will flow into public understanding. In Schmidt et al., there is a move from disagreement, not misunderstanding, to privacy of reasoning. Even were there widespread agreement about the appropriate weighting methods, the above argument would still tell against public releases of weighted LCAs.

The concern may, instead, be this:

- Weighted LCAs function to conceal in technical detail matters that should be aired in the sphere of debates about norms and at the same time infect the technical matter of carrying out an LCA with controversies about norms that are inappropriate to a scientific endeavour.

Call this the scientific integrity argument. In order to consider this, let us broaden the scope of our discussion

\footnotetext{
${ }^{12}$ There are different weighting systems that one may employ. Could there be a meta-weighting: an assessment that contains several of these systems? Such an unreflective approach renders the assessment susceptible to the number of different weighting methods in each area, rather than the reasons that are at stake. Schmidt, Sullivan, and Hofstetter are all in agreement on that point.
}

beyond weighting and consider the workings of the LCA as a scientific endeavour more broadly.

If 'values' are a part of LCAs, it might be the case that some types of values are legitimate parts of it, and some are not. Hertwich et al. forcefully argue against the ISO approach that divides the relevant value judgements into 'value judgements' proper and 'technical assumptions', permitting the latter and not the former [12]. For instance, a particular social discount rate might be seen as a technical assumption, perhaps on the grounds that it is numerical, easily substitutable in the analysis, and forms the basis of a technical comparison. However, those points do not diminish the status of a social discount rate as a value judgement within an analysis, requiring for its validity a defence that rests outside of the analysis and instead in ethics or political theory.

Instead, Hertwich et al. distinguish between 'constitutive', 'contextual' and 'preference' values ${ }^{13}$, holding that while the first two may (or indeed must) exist within legitimately scientific practice, LCA, as a policy guidance tool, goes beyond science and may also include that third category of values. Constitutive values involve 'the acceptance of a scientific theory or paradigm' in the first place. Contextual values involve 'personal, social, cultural, or philosophical emphasis'. Finally, preference values are:

the values that reflect what we care about. Preference values reflect not only the utility of various environmental goods, but also moral values, such as the concern for equity or for future generations, or esthetic values, such as the appreciation for certain landscapes, plants, or animals ([12], p. 21).

On this view, in pure science, one can appeal to values about matters relating to what counts as a good piece of science, or how to present uncertainty about outcomes. But one cannot appeal to values relating to 'preference', that is, about what we aim at and about what fundamentally matters. LCA, on the other hand, 'requires both science and preference values because it not only describes, but also evaluates aspects of reality' ([12], p. 22). As a practice that assesses what would be a better outcome, and makes assumptions about how 'betterness' is to be understood, LCA inevitably grows beyond the scientific method that it rests upon.

In embracing the idea that LCA goes beyond science, this account is on the right track. There is a point of

\footnotetext{
$\overline{13}$ The distinction builds on that made in Shrader-Frechette [30].
} 
caution to be made about the language used in putting the point. The idea that 'preferences' are what mark values as of the type that are beyond science and perhaps to be fed into a technology assessment encourages the idea that such values as equity and utility and justice have similar properties as aesthetic values - a point of contention in philosophy. Indeed, Hertwich et al. appear to follow through on this view of value claims: Whereas the approach suggested here can turn LCA method development and application into objective exercises, its reliance on preferences and the conditions of environmental decision making preclude the existence of uniquely correct methods and results. Competing claims of the environmental superiority of alternative products are therefore permissible ([12], p. 26).

However, there may be right answers to currently controversial normative questions. Perhaps these are very difficult answers to know. In this case, competing claims about the superiority of different products can be permissible, and this situation arises not because of preferences that lack any possible resolution in principle but because the objective truth of the matter about the values at stake is contested and hard to discover. We might thereby retain the 'multiple outputs' approach without committing to the relativism suggested by some of this language. The Hertwich et al. argument is thereby more broadly applicable.

The language of the ISO 14044 standard itself, indeed, encourages this narrowing:

Different individuals, organizations and societies may have different preferences; therefore it is possible that different parties will reach different weighting results based on the same indicator results or normalised indicator results. ${ }^{14}$

Again, we would caution against the relativistic use of the term 'preferences' to incorporate both conceptions of fairness and justice and also expressions of mere liking.

\section{Multiple Outputs and Stakeholders}

The challenge remains: how to use LCA, given its entanglement with what matters, in a way that is legitimate, given widespread uncertainty and disagreement about

$\overline{{ }^{14} \text { ISO } 140442006: \text { s.4.4.3.4.2 }}$ what matters. There is an emerging mainstream answer to that question, urging that we embrace the possibility of multiple outputs, consult stakeholders and carry out assessments in an anticipatory way. In this section we lay out these ideas. In the following section, we set out some doubts and sketch another (complementary) response.

The multiple output approach urges that several assessments should be run in parallel, each reflecting different value sets. In this spirit, Hofstetter et al. put forward:

three structurally identical types of LCA, each based on one coherent but different set of values. These sets of values can be derived from the Cultural Theory and are labeled as 'egalitarian', 'individualistic', and 'hierarchic'.

Two further sets of values, labelled 'fatalist' and 'hermits', are deemed to be opposed to or uninterested in LCA altogether. The approach does provide a framework for providing multiple outputs from a single set of inputs in an assessment [31]. And it may be of use in developing products for market, where there is a demand for the ability to recognize what will be of interest to different sections of a population.

However, this way of running an analysis faces the difficultly that it is insufficiently clear that the five sets of value are meaningfully distinct and useful categories. Can one hold a mixture of several? If it is common to do so, then there ought to be far more than three analyses. If it is uncommon or impossible to combine the value sets proposed, then one would expect there to be a strong empirical base for their existence-and it is far from clear that this basis exists, notwithstanding the appeal to cultural theory. In addressing that point, Steen distinguishes between two broad value sets, 'weak sustainability' and 'strong sustainability', and shows how an LCA might proceed on the terms of each [26]. This has the advantage of mapping values on to a more readily recognizable set of possible purposes of an LCA and tapping directly into its technical functioning. Nonetheless, some will take the view that there remains a danger that supposed disagreements about value sets will be artificially imposed upon the data. Further, creating complicated assessments with multiple outputs may increase accuracy at the cost of clarity: complex outcomes of assessments with multiple possible outputs are difficult to parse. 
Both considerations speak in favour of including stakeholders in the process. Wender et al. argue:

As opposed to a practitioner making these [value] decisions in isolation, environmental LCA should employ social science engagement methods to identify impacted stakeholders, elicit their value preferences, and use these numerous - often conflicting - perspectives to inform modeling decisions. $^{15}$

By using disagreements about values derived from stakeholders, the multiple outputs will be more organic. Further, the output can be expected to be more comprehensible, since the root of any disagreement can be traced to its source in the views of stakeholders. Acceptance of complicated outputs from assessments, then, speaks in favour of stakeholder consultation.

In this spirit, some propose modifications of LCA that incorporate responsible research and innovation processes. For example, 'social LCA' includes reference to stakeholders in the following terms:

In the UNEP-SETAC S-LCA 'the impact categories should reflect internationally recognized categorizations/standards ... and/or result from a multi-stakeholder process'. ([32], pp. 55)

It may be noted that this approach still does not mandate a structured stakeholder consultation. Other sophisticated processes are being proposed. Matthews et al. lay out what they label 'constructive sustainability assessment', which locates LCA within a full framework of responsible research and innovation:

...the power of analytical approaches like LCA is maximised when they are grounded within a broader, more deliberative framework.

We have also explored more participatory and deliberative frameworks such as RRI which offer an alternative, more qualitative and reflective perspective... We argue that combining these frameworks, with a dedicated period of evidence and data collection using tools like LCA, can offer enhancements. ([33], p. 69)

\footnotetext{
${ }^{15}$ They also note: "While stakeholder engagement is discussed in ISO standards for environmental LCA, practitioners typically do not have the requisite training to identify affected parties and elicit the relevant value preferences.” ([3], p. 202).
}

It should also be noted that alongside proposals for stakeholder representation and involvement, there is an accompanying call for anticipatory LCA, whereby assessments are carried out early on in research, perhaps with a higher degree of speculation, and are then repeated later on [3]. Such a practice further permits the categories of assessment to develop in accordance with ongoing assessments and is in accordance with the way that early consideration of impacts and consultation about them provides a way for hidden policy issues to be identified [34].

\section{Doubts and a Proposal}

There are limitations to blanket advocacy of multiple output, stakeholder-consulted LCAs. The involvement of stakeholders is not free or even cheap and includes bureaucratic and time costs. Some research can be expected to yield little of concern for non-research stakeholders or little that is new. There is, in principle, a danger that earlier, more conceptual research may be inhibited by a call to involve stakeholders, where practical issues are unlikely to be uncovered.

Furthermore, it is not obvious a priori that assessments of technology should map on to research projects. That is to say, we should consider the science system as a whole, rather than each project one by one. There is potential for inefficient overlaps of consultation, whether simultaneously or over time. For example, regarding the BISIGODOS LCA, there were other similar LCAs on other projects investigating the derivation of commercial products for algal oils, the project was exploratory, and other LCAs would be involved in related projects in the future. In this sense, non-anticipatory LCAs can be anticipatory of future research projects and thereby meet the concerns of those advocating the need to carry out technology assessments at a relatively early stage of development. Similarly, so long as stakeholders are consulted about a technology type sufficiently, it is unclear that the marginal benefits of consultation on each project will outweigh the marginal costs.

In general, LCA is a tool, and can legitimately be used for different purposes, not all of them consultative. Stakeholder engagement is neither sufficient for appropriately dealing with the inevitable involvement of what matters in designing LCA nor is it at every point necessary. 
The increasing appeal to RRI raises an independent concern, which is that the framework has not yet extended to direct attention towards large catastrophes. People commonly display serious quirks of judgment when making assessments of risks that have either very high impacts or very low probabilities, and accordingly judgments of high impact, low probability risks are especially poor [35]. For instance, insofar as our tendency to assess probability is based in previous experience, there is a framing effect, whereby we will tend irrationally to discount the chances of unfamiliar scenarios in which we do not exist. Such a tendency can affect the integrity of consultations of stakeholders, unless it is directly addressed. Although in the last decade there has been an increasingly sophisticated literature on the subject, ${ }^{16}$ catastrophic risks have not yet entered the lexicon of RRI, and there is a danger that by taking on the emphasis on stakeholder consultation that exists within RRI, LCA could further compound this gap. This effect could be aggravated by the leanings of LCA towards inputs that can be stated with greater certainty. For example, it has been noted that in the field of nanoparticles, it is common for LCAs to run from cradle to gate (i.e., before transportation to the consumer), instead of cradle to grave (which would include the effects of distribution, consumption and disposal). Even though the methodology would strictly require the latter, researchers are also inhibited by a lack of data ([37], p. 71). That inhibition will not prime assessors well for consideration of one-off, large-scale catastrophes, which are especially difficult to fit withinfor example - an expected utility function.

We have looked at two types of response to the existence of value judgements within LCAs: building in multiple outputs and incorporating stakeholder consultations. Not only are they strong complements, they have a conceptual feature in common. This is that they identify ways to outsource the value judgements involved in LCAs into external processes. The multiple values approach seeks to state different outputs based upon different possible assessment patterns and to allow those consuming the assessment to decide which to apply. The stakeholder consultation approach seeks to place consideration of normative issues in the hands of those being consulted.

We conclude by urging the inevitability of a third, complementary approach, which we might call 'researcher awareness'. This holds that those commissioning and carrying out the assessments will themselves

\footnotetext{
${ }^{16}$ For a recent overview, see Ord [36].
}

bring judgements of the type that we have described into the process, and that rather than merely delegating such judgements to others, we can improve assessments by recognizing the existence and influence of such judgements, and further, that recognizing them explicitly is a way to improve them. Happily, it is increasingly common for researchers, too, to be versed in questions, such as what kinds of impact are socially relevant for making an assessment? What should we expect of people's own behaviour change? How are different kinds of impact to be weighed against one another? How is risk and uncertainty to be treated, and how far should distant future costs be discounted? How far can we countenance possibilities in which production in other industries changes? In such a light, it would be hubristic to ask that a systematic assessment could provide an objective comparison of the impact of one product and another. An example of this in action is the use of different forms of multi-criteria decision analysis as a way to aid overall technology assessments that incorporate sustainability, toxicity and economic concerns ([37], p. 71). This is not to say that all scientists must at all times always be policy or ethics experts, or that value judgements should never be outsourced. The point, rather, is that it is better for practitioners to embrace rather than deny the entanglement of ethical and political elements within LCAs; to be aware of the multiple ways that they arise, as we have described; and to be prepared to confront them early on in the research process. It is becoming more common for LCAs to be used as evidence by decision makers, and so in order to maximize their potential and to ensure they are fit for purpose, it is critical that as much information as possible has been considered by the practitioner from the outset and is included in the full assessment of any given scenario-including information about the value-laden nature of the assessment.

Open Access This article is licensed under a Creative Commons Attribution 4.0 International License, which permits use, sharing, adaptation, distribution and reproduction in any medium or format, as long as you give appropriate credit to the original author(s) and the source, provide a link to the Creative Commons licence, and indicate if changes were made. The images or other third party material in this article are included in the article's Creative Commons licence, unless indicated otherwise in a credit line to the material. If material is not included in the article's Creative Commons licence and your intended use is not permitted by statutory regulation or exceeds the permitted use, you will need to obtain permission directly from the copyright holder. To view a copy of this licence, visit http://creativecommons.org/licenses/by/4.0/. 


\section{References}

1. Weidema B (2014) Has ISO 14040/44 failed its role as a standard for life cycle assessment. J Ind Ecol 18(3):324-326

2. Sala S, Reale F, Cristobal-Garcia J, Marelli L, Pant R (2016) Life cycle assessment for the impact assessment of policies. European Commission, Ispra

3. Wender BA, Foley RW, Hottle TA, Sadowski J, PradoLopez V, Eisenberg DA, Laurin L, Seager TP (2014) Anticipatory life-cycle assessment for responsible research and innovation. J Responsible Innov 1(2):200-207

4. Stranddorf HK, Hoffmann L, Schmidt A (2005) LCA technical report: impact categories, normalization and weighting in LCA. Update on selected EDIP97-data. FORCE Technology-Dk-TEKNIK. https://lca-center.dk/wpcontent/uploads/2015/08/LCA-technical-report-impactcategories-normalisation-and-weighting-in-LCA.pdf. Accessed Nov 2020

5. Guinée JB, Gorrée M, Heijungs R, Huppes G, Kleijn R, De Koning A, Van Oers L, Sleeswijk AW, Suh S, do de Haes HAU, van Duin R, Huijbregts MAJ (2002) Handbook on Life Cycle Assessment. An Operational Guide to the ISO standards. Kluwer Academic Publishers, Dordrecht

6. European Commission (2019) The development of the PEF and OEF methods. https://ec.europa.eu/environment/eussd/smgp/dev methods.htm. Accessed Nov 2020

7. Jolliet O, Margni M, Charles R, Humbert S, Payet J, Rebitzer G, Rosenbaum R (2003) IMPACT 2002+: a new life cycle impact assessment methodology. Int J Life Cycle Assess 8(6):324

8. Huijbregts MAJ, Steinmann ZJN, Elshout PMF, Stam G, Verones F, Vieira M, Zijp M, Hollander A, van Zelm R (2017) ReCiPe2016: a harmonised life cycle impact assessment method at midpoint and endpoint level. Int J Life Cycle Assess 22(2):138-147

9. Goedkoop M, Spriensma R (1995) The eco-indicator 95. PRé Consultants, Amersfoort

10. Dreyer LC, Niemann AL, Hauschild MZ (2003) Comparison of three different LCIA methods: EDIP97, CML2001 and eco-indicator 99. Int J Life Cycle Assess 8(4):191-200

11. Benedikter R, Kühne K, Benedikter A, Atzeni G (2016) "Keep it in the ground." The Paris agreement and the renewal of the energy economy: toward an alternative future for globalized resource policy. Challenge 59(3):205-222

12. Hertwich EG, Hammitt JK, Pease WS (2000) A theoretical foundation for life-cycle assessment. J Ind Ecol 4(1):13-28

13. Read R, O'Riordan T (2017) The precautionary principle under fire. Environ Sci Policy Sustain Dev 59(5):4-15

14. John S (2010) In defence of bad science and irrational policies: an alternative account of the precautionary principle. Ethical Theory Moral Pract 13(1):3-18

15. Laurent A, Hauschild MZ (2015) Normalisation. In: Hauschild MZ, Huijbregts MA (eds) Life Cycle Impact Assessment. Springer, Dordrecht, pp 271-300

16. Caney S (2014) Climate change, intergenerational equity, and the social discount rate. Politics, Philosophy and Economics 13(4):320-342

17. Broome J (2017) Weighing goods: equality, uncertainty and time. John Wiley \& Sons, Oxford
18. Searchinger T, Heimlich R, Houghton RA, Dong F, Elobeid A, Fabiosa J, Tokgoz S, Hayes D, Yu T-H (2008) Use of U.S. croplands for biofuels increases greenhouse gases through emissions from land-use change. Science 319 (5867):1238-1240

19. Curran MA (2017) Overview of goal and scope definition in life cycle assessment. In: Curran M (ed) Goal and scope definition in life cycle assessment. LCA compendium - the complete world of life cycle assessment. Springer, Dordrecht, pp 1-62

20. Suh S, Yang Y (2014). On the uncanny capabilities of consequential LCA. Int J Life Cycle Assess 19(6):11791184

21. Plevin RJ, Delucchi MA, Creutzig F (2014) Using attributional life cycle assessment to estimate climate-change mitigation benefits misleads policy makers. J Ind Ecol 18(1): 73-83

22. Consequential-LCA (2015) Why and when? https://consequential-lca.org/clca/why-and-when/. Accessed Nov 2020

23. Weidema BP, Pizzol M, Schmidt J, Thoma G (2018) Attributional or consequential life cycle assessment: a matter of social responsibility. J Clean Prod 174:305-314

24. Baitz M (2017) Attributional life cycle assessment. In: Curran M (ed) Goal and scope definition in life cycle assessment. Springer, Dordrecht, pp 123-143

25. Hall MR (2015) A transdisciplinary review of the role of economics in life cycle sustainability assessment. Int J Life Cycle Assess 20(12):1625-1639

26. Steen B (2006) Describing values in relation to choices in LCA. Int J Life Cycle Assess 11(4):277-283

27. Schmidt W-P, Sullivan J (2002) The value debate: weighting of life cycle assessments in a global context: global diversity exists and has to be valued. Int J Life Cycle Assess 7(4): Art. 250

28. Hofstetter P (2002) The value debate: ecodesign in a global context are there differences in global values and do they matter. Int J Life Cycle Assess 7(2): Art 62

29. Pizzol M, Laurent A, Sala S, Weidema B, Verones F, Koffler C (2017) Normalisation and weighting in life cycle assessment: quo vadis. Int J Life Cycle Assess 22(6):853866

30. Shrader-Frechette KS (1991) Risk and rationality: philosophical foundations for populist reforms. University of California Press, Berkeley

31. Hofstetter P, Baumgartner T, Scholz RW (2000) Modelling the valuesphere and the ecosphere: integrating the decision makers' perspectives into LCA. Int J Life Cycle Assess 5(3): Art. 161

32. Thorstensen E, Forsberg E-M (2016) Social life cycle assessment as a resource for responsible research and innovation. J Responsible Innov 3(1):50-72

33. Matthews NE, Stamford L, Shapira P (2019) Aligning sustainability assessment with responsible research and innovation: towards a framework for constructive sustainability assessment. Sustain Prod Consum 20: 58-73

34. Collingridge D (1980) The social control of technology. St. Martin's Press, New York

35. Yudkowsky E (2011) Cognitive biases potentially affecting judgment of global risks. In: Bostrom N, Cirkovic MM (eds) Global catastrophic risks. Oxford University Press, Oxford 
36. Ord T (2020) The precipice: existential risk and the future of humanity. Bloomsbury, New York

37. Windsor R, Cinelli M, Coles SR (2018) Comparison of tools for the sustainability assessment of nanomaterials. Curr Opin Green Sustain Chem 12:69-75
Publisher's Note Springer Nature remains neutral with regard to jurisdictional claims in published maps and institutional affiliations. 